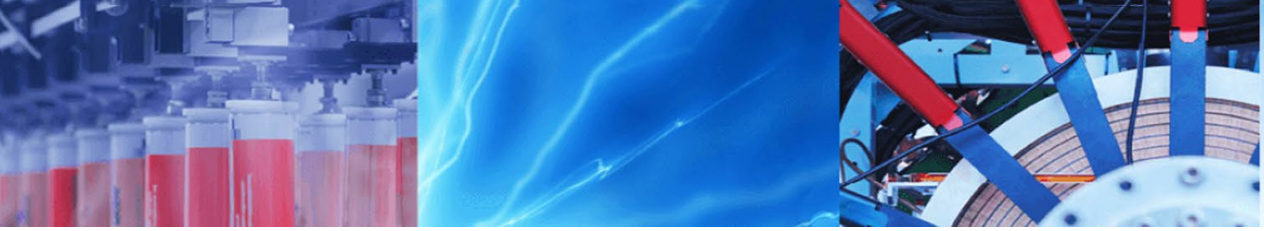

Research Article

\title{
Structural and thermal characterization of cellulose and copper oxide modified cellulose obtained from bamboo plant fibre
}

\author{
Elias E. Elemike ${ }^{1} \cdot$ Damian Onwudiwe $^{2,3} \cdot$ Wisdom Ivwurie $^{1}$
}

Received: 15 December 2019 / Accepted: 11 September 2020 / Published online: 23 September 2020

(c) Springer Nature Switzerland AG 2020

\begin{abstract}
Cellulose and their modified forms are important materials for various applications including surface coatings, food and drug formulations, and confectioneries and as intermediates for other chemical products. This study focuses on the nonconventional production of cellulose from abundant bamboo plant and the structural effects arising from modifications of the obtained cellulose. The bamboo fibre was treated with alkali and bleached to produce cellulose which was further modified with ethylene and propylene oxides and $\mathrm{CuO}$ nanoparticles. They were characterised with Fourier-transform infrared spectroscopy (FTIR), Scanning electron microscopy (SEM), energy dispersive X-ray and thermogravimetric analyser-differential scanning calorimeter (TGA-DSC). This approach gave interesting structural differences among the cellulose and the modified forms. From the TGA analyses, the $\mathrm{CuO}$ nanoparticles impregnated cellulosic material exhibited the greatest stability. The raw bamboo fibre appeared as stacked porous nanotubes as shown by the SEM different from other morphologies while the FTIR displayed similar peaks with minor differences. The nature and behaviour of the modified cellulosic materials suggest applications especially in paint formulation and as nano carriers.
\end{abstract}

Keywords Cellulose · Thermal analysis · Nanocomposites · Morphology

\section{Introduction}

Cellulose is a major polysaccharide from bacteria and plants and they are important polymers used in various industrial applications such as in nanocomposites, paints, sensors, cosmetics and biomedicines [6]. The molecules of the cellulose are made up of $1,4-\beta-D-$ anhydroglucopyranose units joining the hydroxyl groups by hydrogen bonds. It is insoluble in water and can easily be extracted from the components of a plant.

Cellulose and their derivatives are among the most utilized natural substances and have become a relevant commercial raw material in the petrochemical industry, waste and oil clean-up, textiles and paper manufacturing, food and pharmaceutical formulations [4, 20]. The major wellspring of cellulose is in the plant fibers (cotton, jute, hemp and flax) and of course, wood (about $42 \%$ cellulose).

However, they influence to a great extent the chemical properties of the plant fibres and contain an average of $35-50 \%$ of the plant fibres depending on the type of the plant material. Cotton, for example, has over $90 \%$ cellulose content whereas bamboo contains about $40-55 \%$ cellulose which is great and should be tapped since it is in abundant supply in Nigeria.

They are biodegradable, available, sustainable and renewable which makes their investigation an interesting and continuous one. Nanocrystalline celluloses have endearing characteristics such as high surface area, high crystallinity, low density, excellent mechanical strength and special morphology [10].

$\triangle$ Elias E. Elemike, chemphilips@yahoo.com | 'Department of Chemistry, Federal University of Petroleum Resources, P.M.B. 1221, Effurun, Nigeria. ${ }^{2}$ Material Science Innovation and Modelling (MaSIM) Research Focus Area, Faculty of Natural and Agricultural Science, North-West University (Mafikeng Campus), Private Bag X2046, Mmabatho, South Africa. ${ }^{3}$ Department of Chemistry, Faculty of Natural and Agricultural Science, North-West University (Mafikeng Campus), Private Bag X2046, Mmabatho 2735, South Africa. 
There are different forms of nanocelluloses such as cellulose nanofibrils (CNFs), cellulose nanocrystals (CNCs), and bacterial nanocellulose (BNC) and these forms are due to their sources, mode of preparation, sizes and applications [1]. CNCs could be made by acid hydrolysis and they are characterised by low aspect ratio and high crystallinities $[3,6]$. CNFs on the other hand are prepared using high pressure mechanical agitation, grinding, microfluidization and ultrasonication and they give materials of high aspect ratio. BNC is made from microorganisms and they are of high crystallinity with great degree of polymerization [19].

There are a lot of investigations on modified cellulose and nanocellulose from plant fibres with more underway. Morais et al. have reported the extraction of CNFs structures from raw cotton linter with curled shape which enhances the surface area thereby improving their reactivity [16]. Das et al. (2018), have also prepared cellulose acetate from rice husk with $66 \%$ yield using acetic anhydride and iodine catalyst.

In another study, Candido and Gonçlaves [2], extracted and modified cellulose to cellulose acetate and carboxymethylcellulose from sugarcane straw though with low efficiency of the carboxymethylation reaction due to the presence of lignin.

Marett et al. [12], have also isolated CNCs from pistachio nut waste with yield of $50 \pm 14 \%$, aspect ratio of $17 \pm 3$, surface charge density of $90 \pm 12 \mathrm{mmol} / \mathrm{kg}$ and crystallinity of approx. $66 \%$.

Bamboo plant is considered as an economic plant in Nigeria, and in this investigation, cellulose is extracted from the bamboo plant fibres and modified by mechanical and chemical treatment.

The use of the abundant and non-edible cellulosic materials as promising sources of chemicals and energy is on the increase in recent times due to resource diversification and efforts to sanitize the environment of $\mathrm{CO}_{2}$ emissions.

The incorporation of nanoparticles into cellulose to form nanocomposites is still another emerging area that finds applications in biomedicine, water treatment, bioelectronics, sensing and so on. Hittini [8], reported the efficient application of CuO-cellulose nanocomposites for the detection of $\mathrm{H}_{2} \mathrm{~S}$ gas and offer interesting attributes such as sensitivity, selectivity, energy saving and compactness.

In another work by Hussain et al. [9], cellulose was extracted from cotton and $\mathrm{CuO}$ incorporated to form CuO-cellulose nanorods. The nanocomposites exhibited improved antibacterial properties than orthodox antibacterial agents.

The necessity for green material solutions, sustainable development policy and low environmental impact therefore becomes the drive for this present investigation. This work therefore focuses on the structural and thermal stability nature of cellulose, their modified forms from bamboo plant and incorporation of $\mathrm{CuO}$ nanoparticles into the cellulose for possible industrial applications. In modern times, alkoxy modified cellulose are used as rheology modifiers or thickening agent in chemical processing and the cost is very high. It is therefore important to find alternatives to these thickening agents from available raw materials especially in developing economies like Africa.

\section{Materials and methods}

\subsection{Bamboo fibre (BF) preparation}

The bamboo fiber was obtained from Agbarho, Delta State, Nigeria. It was washed, dried under direct sunlight for 5 days and ground into powder using a planner machine. Afterwards, the bamboo fiber was sieved using a $150 \mathrm{mic}$ size siever to obtain the fine powder.

\subsection{Isolation and modification of the cellulose fibres}

The bamboo fiber $(50 \mathrm{~g})$ was immersed in $17.5 \%(300 \mathrm{~mL})$ sodium hydroxide solution and heated for $3 \mathrm{~h}$ with constant stirring in order to dissolve the pectin and hemicellulose. The mixture was filtered and rinsed severally with deionized water. It was further dried giving the cellulosic bamboo fibre (CBF). The CBF was further bleached using $150 \mathrm{~mL}$ hydrogen peroxide, filtered and dried at $85^{\circ} \mathrm{C}$ for $48 \mathrm{~h}$ to obtain the delignified bamboo fibre (DBF). About $1.5 \mathrm{~g} \mathrm{DBF}$ was sonicated in $50 \mathrm{~mL}$ distilled water and modified by introducing $0.68 \mathrm{M}$ ethylene oxide and $0.17 \mathrm{M}$ propylene oxide to give modified delignified bamboo fibre (MDBF). The mixture was stirred at room temperature $\left(25^{\circ} \mathrm{C}\right)$ for about $3-4 \mathrm{~h}$, filtered and dried for $24 \mathrm{~h}$ and further characterised.

\subsection{Preparation of $\mathrm{CuO}$ nanoparticles and their incorporation into cellulose}

CuO nanoparticles was prepared using Alchornea cordifolia aqeous leaf extracts. The leaf extract was made by boiling the powdered dried leaf in $100 \mathrm{~mL}$ of water at a temperature of about $60{ }^{\circ} \mathrm{C}$ for $45 \mathrm{~min}$. On the other hand, $0.002 \mathrm{M} \mathrm{CuSO}_{4} \cdot 5 \mathrm{H}_{2} \mathrm{O}$ was prepared and the nanoparticles made by heating and stirring $60 \mathrm{~mL}$ of the extract with $300 \mathrm{~mL}$ of the copper salt for about $4 \mathrm{~h}$. The solution was centrifuged, washed and the resulting nanoparticles dried. About $1.5 \mathrm{~g}$ of cellulose nanofibers was sonicated in $100 \mathrm{~mL}$ of deionized water after which $0.5 \mathrm{~g}$ of the synthesized $\mathrm{CuO}$ nanoparticles was impregnated into the solution and stirred for $24 \mathrm{~h}$ to 
form nanocomposite (CuONPs-DBF). The formed nanocomposite was centrifuged and dried at about $50^{\circ} \mathrm{C}$. They were all characterised to evaluate the morphological changes and the structural behaviours brought about by the modifications.

\subsection{Characterization of the isolated cellulose and the CuO-cellulose nanocomposite}

The structural changes in the functional groups were evaluated using the Bruker alpha-P FTIR spectrophotometer FT-IR spectroscopy in the region from 4000 to $400 \mathrm{~cm}^{-1}$.

The morphologies of the materials were analyzed using the Quanta FEG 250 Environmental scanning electron microscope with a tungsten electron source at $30 \mathrm{kV}$. The thermal degradation of the cellulose materials was investigated using the SDT 650 TGA-DSC equipment from TA-Instrument at a heating rate of $10^{\circ} \mathrm{C} / \mathrm{min}$ under nitrogen atmosphere.

\section{Results and discussion}

The chemical treatment with $\mathrm{NaOH}$ and $\mathrm{NaClO}_{2}$ affected the bamboo fibres and changed the colour of the fibres from brownish to white and also removed the lignin, hemicellulose, ash and other non-cellulosic components of the fibre. The possible reaction pathway or product formed is shown in Scheme 1.

\subsection{FTIR spectra analysis}

The FTIR spectra gave the likely chemical components of the raw bamboo fibres and the modified forms as shown in Fig. 1a-d and Table 1. In the raw fibres, there were peaks at $3297.31,2927.25,2853.95,1734.83,1593.60$, $1457.73,1368.35,1234.27$ and $1035.83 \mathrm{~cm}^{-1}$. The $3297.31 \mathrm{~cm}^{-1}$ peak was broad which may be assigned to $\mathrm{OH}$ stretching vibrations of the $\mathrm{CH}_{2} \mathrm{OH}$ groups. The pronounced peak at $1738.07 \mathrm{~cm}^{-1}$ may be due to ester linkages associated with ferulic and $\mathrm{p}$-coumeric acids groups of lignin and/or hemicelluloses in the raw bamboo fibres [3]. In the modified cellulose fibres as shown in Fig. 1b-d, similar spectra were observed but with some differences. The peaks at $3326.03,3297.64$ and $3313.52 \mathrm{~cm}^{-1}$, for DBF, MDBF and CuONPs-DBF respectively were due to the $\mathrm{OH}$ groups but the peaks are more pronounced compared to the raw bamboo fibre signifying more $\mathrm{OH}$ groups [17]. The sharp peak at $1734.83 \mathrm{~cm}^{-1}$ observed at the raw bamboo fibre were absent in the modified samples Fig. $1 \mathrm{~b}-\mathrm{d}$ which is an indication that the noncellulosic components were removed. In all the modified cellulose, intense peaks were seen at $1639,1646.56$ and $1639.37 \mathrm{~cm}^{-1}$ which were vibrations due to $C=0$ stretch of arylketones and/or $\mathrm{C}-\mathrm{H}$ bonds of aromatic rings [18]. In all the spectra, there were outstanding peaks around $1030 \mathrm{~cm}^{-1}$ which could be as a result of the $\mathrm{C}-\mathrm{O}$ morphological bonds and the spike-like peak around $890 \mathrm{~cm}^{-1}$ are representative of the $\beta$-glycosidic linkage of glucose present in the cellulose structure $[6,7]$. The 520.89 and $426.19 \mathrm{~cm}^{-1}$ bands in Fig. $1 \mathrm{~d}$ could be due to the $\mathrm{Cu}$ impregnated in the cellulose [13].
Scheme 1 Reaction pathway for the modification of cellulose from bamboo fibre

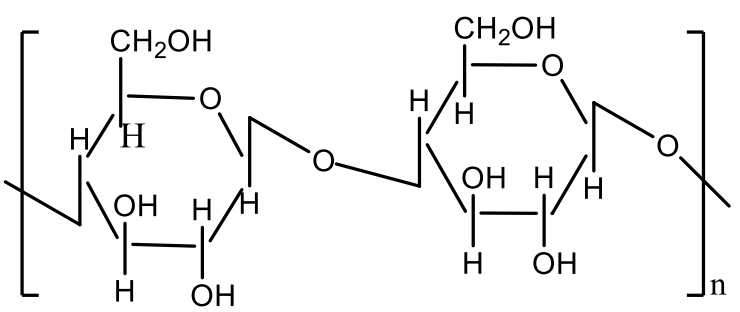<smiles>CO[Nb](O)(O)OC1CC1</smiles>

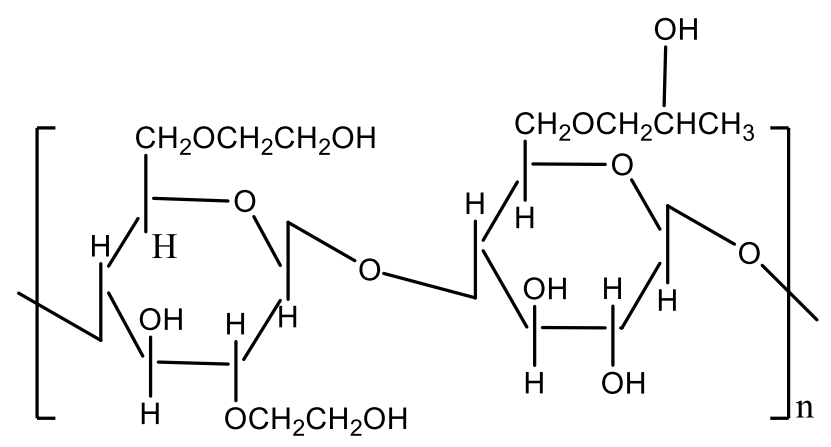


Fig. 1 FTIR spectra of $\mathbf{a} B F \mathbf{b}$ DBF c MDBF d CuONPs-DBF
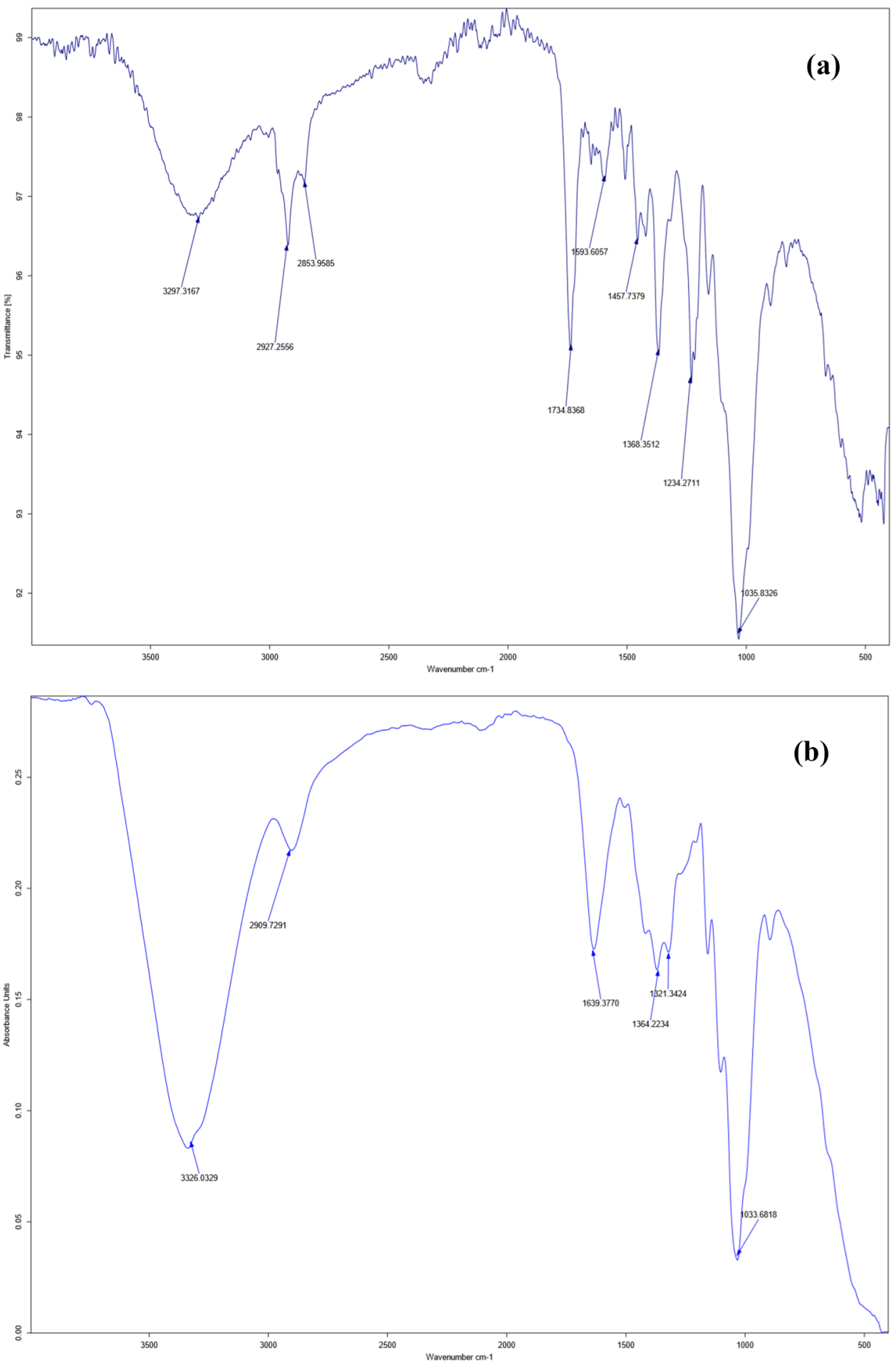

\subsection{Morphological analysis}

The morphologies of the bamboo fibres and the modified cellulose show that there are great changes introduced by the alkaline treatment and also the modification using the epoxides and $\mathrm{CuO}$ nanoparticles. Figure 2a shows the untreated fibre (BF) which appeared as porous nanotubes aligned properly in an ordered manner. Figure $2 b, c$ represent the alkali treated cellulose (DBF) and epoxide modified cellulose (MDBF) respectively which show rough surfaces attributed to possible removal of the non-cellulosic lignin, hemicelluloses, pectin, and wax during the treatment. Figure $2 \mathrm{~d}$ showed dispersed spherical like shapes on the cellulose which is an indication of the impregnation 
Fig. 1 (continued)
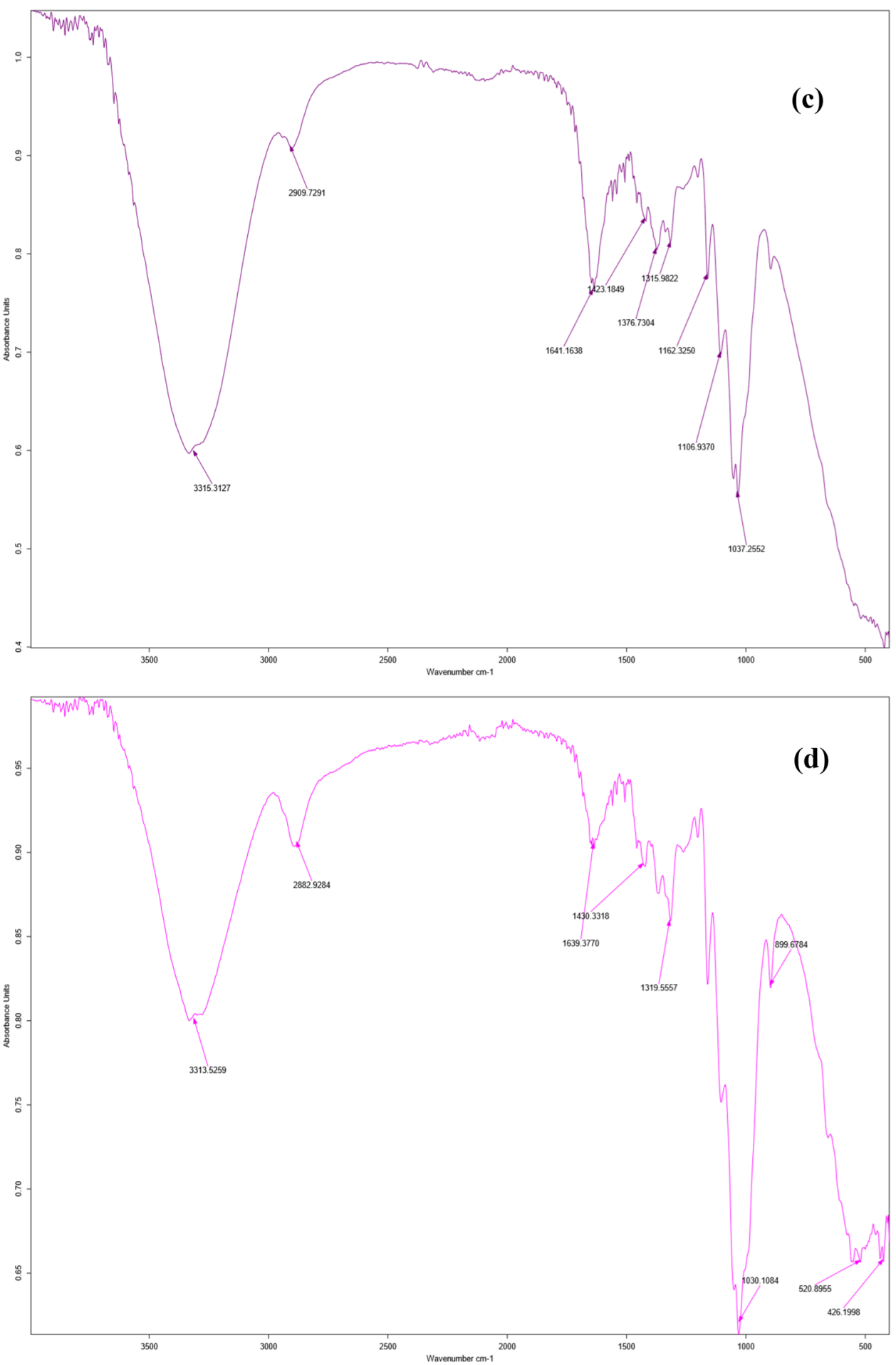

of the $\mathrm{CuO}$ nanoparticles, hence the nanocomposite (CuONPs-DBF).

From all the morphologies, it was evident that the structure of the untreated fibre is totally different from the other modified cellulose materials.

Overall, the energy dispersive X-ray (EDX) spectra placed side by side with the scanning electron microscopic (SEM) images showed that all the materials basically contained carbon and oxygen with other minor elements such as $\mathrm{Ca}, \mathrm{Na}, \mathrm{Cl}$ etc. which may be traces from the chemicals used in treatment or from the bamboo plant. 
Table 1 Spectra bands

\begin{tabular}{lllll}
\hline Groups/samples & BF & DBF & MDBF & CuONPs-DBF \\
\hline OH & 3297.31 & 3326.03 & 3297.44 & 3313.52 \\
CH stretching bands & 2927 & 2909.72 & 2897.22 & 2882.92 \\
& 2835.95 & & & \\
C=O stretch (esters) & 1734.83 & & & \\
C=O stretch & & 1639 & 1646.52 & 1639.37 \\
$\quad$ (ketones), C-H & & & & \\
aromatic rings & & & & \\
& 1593.60 & & & \\
C-H in plane bends & 1457.73 & & & \\
C-H stretch & 1368.35 & 1364.22 & 1369.58 & 1319.55 \\
& 1234.27 & 1321.34 & 1326.70 & \\
C-O & 1035.83 & 1033.68 & 1031.89 & 1030.10 \\
& & & & 899.67 \\
Cu & & & & 426.19 \\
\hline
\end{tabular}

\subsection{Thermal degradation and stability studies}

The thermal analysis of the bamboo derived cellulose and modified cellulose products were carried out using thermogravimetric analysis (TGA) and differential scanning calorimetry (DSC) at a flow rate of $10^{\circ} \mathrm{C} / \mathrm{min}$ under nitrogen gas flow. The TGA and DSC curves are shown in Fig. 3a-d. Figure $3 a$ which represents the raw $B F$ shows that from the initial room temperature to $200^{\circ} \mathrm{C}$, there was about $10 \%$ weight loss which may be due to water desorption resulting from the hydrophilic nature of the lignocellulose fibres [11]. Between the temperatures of $200-400{ }^{\circ} \mathrm{C}, 57.34 \%$ of the material decomposed which explained that the degree of polymerisation of the material gradually decreased [4]. The highest degradation rate occurred at a temperature of about $300^{\circ} \mathrm{C}$. The DSC curve showed three endotherms at 198,610 and $770{ }^{\circ} \mathrm{C}$ for BF. The peak at $198^{\circ} \mathrm{C}$ was the highest endothermic reaction and corresponded to the initial TG breakdown of the material and the largest weight loss. After $993^{\circ} \mathrm{C}$, about $78.94 \%$ of the crystalline portion of the material has been decomposed to leave amorphous structure of about $21.06 \%$ residue.

For $\mathrm{DBF}$, the degradation reaction started from the onset showing more crystalline nature of the material. At a temperature of $176{ }^{\circ} \mathrm{C}$ about $40 \%$ of the cellulose has decomposed as shown in Fig. 3b. The peak decomposition temperature was noticed at $290^{\circ} \mathrm{C}$. At $936.33^{\circ} \mathrm{C}$, only $4.1 \%$ of the sample was left as residue. Many endothermic peaks were observed in the DSC curves of the DBF, which could be attributed to different internal processes. The initial endothermic peak at 195 corresponded to largest weight loss in the TGA curve, and the final endotherms at $935^{\circ} \mathrm{C}$ was due to the final decomposition, resulting into the residue obtained.

Figure $3 \mathrm{C}$ shows that at a temperature of $250^{\circ} \mathrm{C}$, about $25 \%$ of the MDBF cellulose material degraded and at $305^{\circ} \mathrm{C}$, the greater percentage of the modified cellulose material was seen to be lost. DSC curve reveals endothermic peaks at 275 and $363^{\circ} \mathrm{C}$ which may be attributed to the loss of the two major organic moieties of ether (epoxide) functional groups and cellulose. The higher degradation peak temperature observed in MDBF compared to
Fig. 2 SEM and EDX analysis of a BF b DBF c MDBF d CuONPsDBF

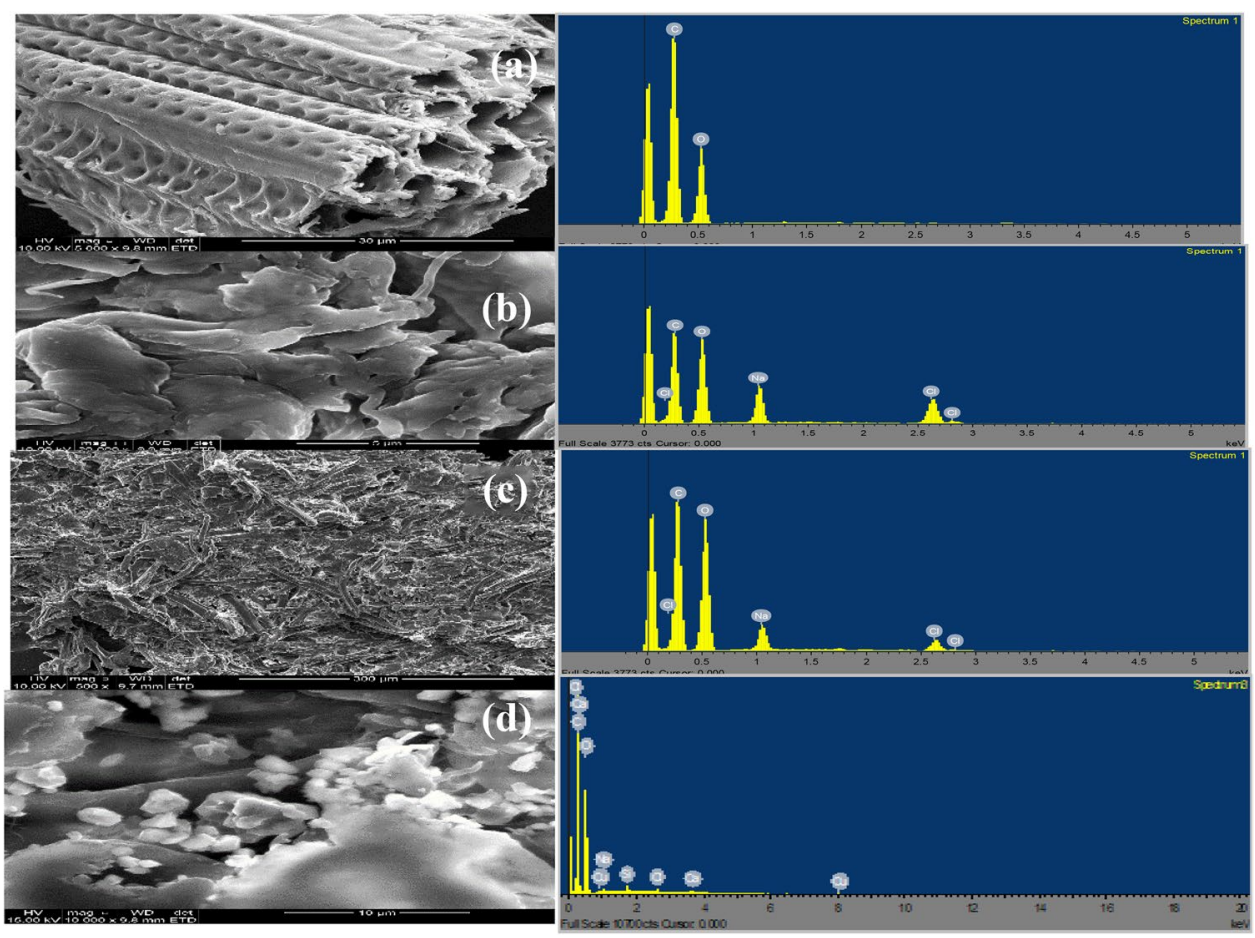



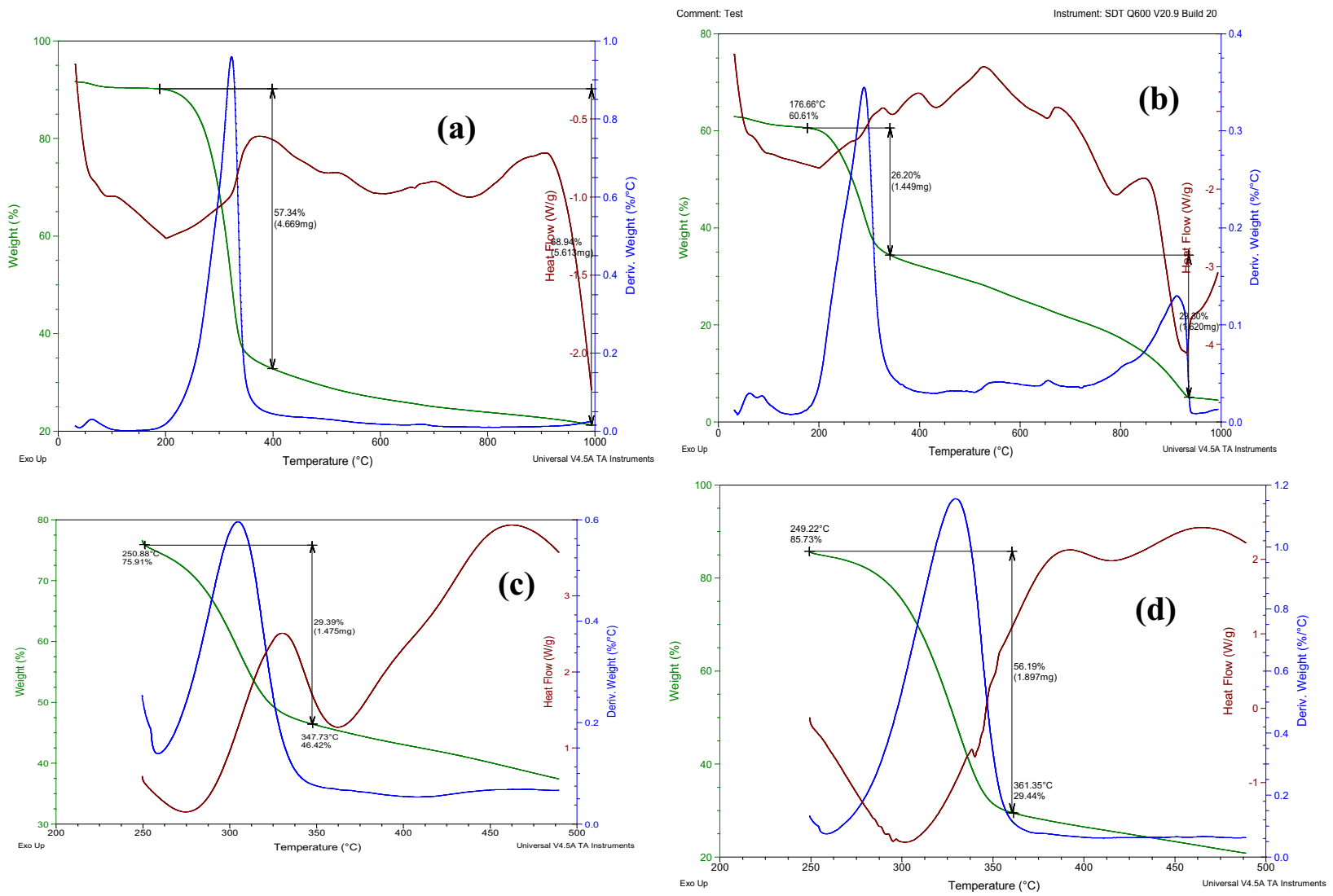

Fig. 3 DSC-TGA thermograms of the processed cellulose materials a BF $\mathbf{b}$ DBF $\mathbf{c}$ MDBF $\mathbf{d}$ CuONPs-DBF

BF and DBF shows more thermal stability of the modified product.

The incorporation of $\mathrm{CuO}$ nanoparticles into the cellulose structure to form CuONPs-DBF shows that thermal stability of the nanocomposite was enhanced. There was about $15 \%$ weight loss at temperature of approx $250{ }^{\circ} \mathrm{C}$ compared to $25 \%$ loss at the same temperature in the case of the MDBF as shown in Fig. 3c, d. The peak temperature of decomposition recorded was at $330^{\circ} \mathrm{C}$. However, within the temperatures of $249-361{ }^{\circ} \mathrm{C}, 56 \%$ of the material was degraded leaving about $29 \%$ of the composite material.

The DSC curve explains the heat energy involved in the reactions and are represented by the endothermic peaks at 300 and $412{ }^{\circ} \mathrm{C}$ in the CuONPs-DBF, an indication of disruption of intramolecular bonds from the cellulose and the introduced components. The diminished endothermic peak around $341^{\circ} \mathrm{C}$ may be due to crystalline phase change $[14,15]$. When the endothermic peaks are compared to others (BF, DBF, MDBF), the CuONPs-DBF nanocomposite showed the highest stability.

From the results, it can be seen that the $\mathrm{BF}$ underwent some changes to give DBF, MDBF and CuONPs-DBF considering the damage on the crystallinity of the modified products [5].

\section{Conclusion}

Cellulose was successfully extracted from bamboo plant by hydrothermal treatment with $\mathrm{NaOH}$ and $\mathrm{NaClO}_{2}$. These chemical reagents assisted in the removal of hemicellulose and lignin content of the bamboo fibre. The delignified bamboo fibre or the obtained cellulose showed the least stability among others which indicates its better crystallinity whereas the CuONPs-DBF was the most thermally stable material. The FTIR and SEM results were good evidence that showed the interaction of the cellulose with CuO NPs and their possible dispersion in the entire matrix. Further studies would be carried out on the modification or substitution of the obtained cellulose as substantial degree of substitution could not be ascertained. However, the obtained structural results from this work provides information towards the potential development of this nonconventional source of cellulose and can be important for 
a diverse range of applications especially in paint formulation and as nanocarriers in biomedical fields.

Acknowledgements The authors are sincerely grateful to Dr Innocent Shuro for the SEM and EDX analysis.

\section{Compliance with ethical standards}

Conflict of interest The authors declare no conflict of interest in this work.

\section{References}

1. Abdul Khalil HPS, Davoudpour Y, Islam MN, Mustapha A, Sudesh K, Dungani R (2014) Production and modification of nanofibrillated cellulose using various mechanical processes: a review. Carbohydr Polym 99:649-665

2. Candido RG, Gonçalves AR (2016) Synthesis of cellulose acetate and carboxymethylcellulose from sugarcane straw. Carbohydr Polym 152:679-686

3. Chen W, Yu H, Liu Y, Hai Y, Zhang M, Chen P (2011) Isolation and characterization of cellulose nanofibers from four plant cellulose fibers using a chemical-ultrasonic process. Cellulose 18:433-442

4. Das AM, Ali AA, Hazarika MP (2014) Synthesis and characterization of cellulose acetate from rice husk: eco-friendly condition. Carbohydr Polym 112:342-349

5. Eyley S, Thielemans W (2014) Surface modification of cellulose nanocrystals. Nanoscale 6:7764-7779

6. Feng Y, Cheng T, Yang W, Ma P, He H (2018) Characteristics and environmentally friendly extraction of cellulose nano fi brils from sugarcane bagasse. Ind Crop Prod 111:285-291

7. Hemmati F, Mahdi S, Kashaninejad M, Barani M (2018) Synthesis and characterization of cellulose nanocrystals derived from walnut shell agricultural residues. Int J Biol Macromol 120:1216-1224

8. Hittini W, Abu-Hani AF, Reddy N, Mahmou ST (2020) Cellulosecopper oxide hybrid nanocomposites membranes for $\mathrm{H}_{2} \mathrm{~S}$ gas detection at low temperatures. Sci Rep 10(2940):1-9
9. Hussain RK, Aziz WJ, Ibrahim IA (2019) Antibacterial activity of CuO-Cellulose nano rods depends on anew green synthesis (cotton). J Nanostruct 9(4):761-767

10. Ilyas RA, Sapuan SM, Ishak MR (2018) Isolation and characterization of nanocrystalline cellulose from sugar palm fibres (Arenga pinnata). Carbohydr Polym 181:1038-1051

11. Johar N, Ahmad I, Dufresne A (2012) Extraction, preparation and characterization of cellulose fibres and nanocrystals from rice husk. Ind Crop Prod 37:93-99

12. Marett J, Aning A, Foster EJ' (2017) The isolation of cellulose nanocrystals from pistachio shells via acid hydrolysis. Ind Crop Prod 109:869-874

13. Moniri S, Ghoranneviss M, Hantehzadeh MR, Asadabad MA (2017) Synthesis and optical characterization of copper nanoparticles prepared by laser ablation. Bull Mater Sci 40:37-43

14. Ondru`sova $D$, Jona $E$, Simon $P$ (2002) Thermal properties of $\mathrm{N}$-ethyl-N phenyldithiocarbamates and their influence on the kinetics of cure. J Therm Anal Cal 67:147

15. Onwudiwe DC, Arfin T, Strydom CA (2014) Fe(II) and Fe(III) complexes of $\mathrm{N}$-ethyl-N-phenyl dithiocarbamate: electrical conductivity studies and thermal properties. Electrochim Acta 127:283-289

16. Paulo J, Morais S, De FM, De M, De SM, Dias L (2013) Extraction and characterization of nanocellulose structures from raw cotton linter. Carbohydr Polym 91:229-235

17. Penjumras $P$, Rahman RBA, Talib RA, Abdan K (2014) Extraction and characterization of cellulose from durian rind. Agric Agric Sci Procedia 2:237-243

18. Rahbar K, Heidari H, Rashidi A (2016) Preparation and evaluation of nanocrystalline cellulose aerogels from raw cotton and cotton stalk. Ind Crop Prod 93:203-211

19. Xiang Z, Gao W, Chen L, Lan W, Zhu JY, Runge T (2016) A comparison of cellulose nanofibrils produced from cladophora glomerata algae and bleached eucalyptus pulp. Cellulose 23:493-503

20. Yan L, Li W, Qi Z, Liu S (2006) Solvent-free synthesis of cellulose acetate by solid superacid catalysis. J Polym Res 13:375-378

Publisher's Note Springer Nature remains neutral with regard to jurisdictional claims in published maps and institutional affiliations. 